\title{
URINARY EXCRETION OF FREE NORADRENALINE AND ADRENALINE IN TRAINED AND UNTRAINED MEN
}

\author{
B. DAVIES, Ph.D., ${ }^{1}$ B. H. MASSEY, Ph.D., ${ }^{2}$ \\ T. G. LOHMAN, Ph.D., ${ }^{2}$ and B. T. WILLIAMS, M.D. ${ }^{3}$ \\ ${ }^{1}$ Department of Physical Education and Recreation, Preston Polytechnic, UK \\ ${ }^{2}$ Physical Fitness Research Laboratory, University of IIIinois, USA \\ ${ }^{3}$ Department of Pathology, Mercy Hospital, Champaign, Illinois, USA
}

\begin{abstract}
Measurements of free noradrenaline and adrenaline were made in the urine of $\mathbf{2 8}$ men sampled after rest and exercise prior to, and following six and twelve weeks of an exercise programme. The training consisted of thirty minutes of running and walking four times per week at an intensity estimated at $75 \%$ of the age-predicted maximum heart rate. A fifteen minute standardized cycle ergometer work test was conducted on all subjects prior to the training and following six and twelve weeks of training. Noradrenaline and adrenaline excretions in the urine were measured before and after the work test.
\end{abstract}

Significant decreases in noradrenaline excretion measured during rest and after exercise were found in the training group, while the excretion levels of catecholamines increased or remained the same for the untrained group throughout the study.

It was concluded that resting and exercise catecholamines were lowered in the subjects who participated in an exercise programme, and that the changes are more apparent in noradrenaline than adrenaline.

\section{INTRODUCTION}

Considerable evidence indicates that physical activity of sufficient intensity and duration may have a prophylactic effect on the incidence of coronary heart disease (Ekstein, 1957; Wolffe, 1957; Brunner, 1971; Harrison, 1972; Kannel et al., 1971; Hawthorn, 1976). Mechanisms by which physical activity affects coronary heart disease are not well understood. High levels of catecholamines have been shown to be pathogenic and destructive on the cardiovascular system (Robertson and Peyser, 1951; von Euler, 1955; Regan et al., 1966).

Few attempts have been made to evaluate the changes in catecholamine secretion associated with exercise training. Von Euler (1969) has proposed that urinary catecholamines can be used as an index of effort in performance of a set work task. De Schryver et al., (1967) found a highly significant decrease (34\%) in the catecholamine content of the heart tissue in spontaneously running rats. Wolfson et al., (1972) examined the effects of conditioning on plasma catecholamine levels during exercise in patients with coronary artery disease. At peak work loads the heart rates and plasma catecholamines were reduced in conditioned patients. Cronan and Howley (1974) found no change in the catecholamine excretions of nine adult males following eight weeks training. The present study was designed to in- vestigate the excretion of noradrenaline and adrenaline following rest and exercise in men after engaging in a three month running training programme.

\section{METHODS}

\section{Subjects}

The subjects for study were 28 men volunteers ranging in age from 22 to 39 years, all of whom were considered in good health based on a medical examination. Prior to the experiment none of the men had participated in regular exercise on a systematic basis. Eighteen volunteered to participate in the supervised exercise programme. The remaining ten were recruited as control subjects. These men did not participate in strenuous activity, and were requested to maintain their normal living patterns throughout the experiment.

\section{Procedure}

The subjects were tested twice before training (reference point 1), after six weeks training (reference point 2) and after twelve weeks training (reference point 3). The measurements of catecholamine levels after rest and exercise, and heart rate during exercise at each reference point were repeated with one day intervening between tests and the mean data from the test/retest sessions were used in the statistical analysis. Body weight and an 
estimate of lean body mass utilising three skinfold sites according to the method of Pascale et al., (1955) were recorded on the first test day at each reference point. Blood pressure was recorded before training began with the subject supine following thirty minutes rest. The pressures were normal systolic $120 \pm 10 \mathrm{~mm} \mathrm{Hg}$. and diastolic $80 \pm 10 \mathrm{~mm} \mathrm{Hg}$. Urine examination for protein, glucose, ketones, bilirubin and blood also proved normal. No subject received drugs which might interefere with the determination of the catecholamines. Throughout testing, the room temperature was maintained by air conditioninig at $25^{\circ} \pm 2^{\circ} \mathrm{C}$.

Resting catecholamine excretion was obtained having the subjects empty their bladders fifteen minutes after arrival at the laboratory. After bed rest for sixty minutes a urine sample was collected. Immediately after voiding the Resting sample, each subject cycled for 15 minutes on a Monark ergometer at a work load of 125 watts. Following the exercise the subjects reclined on a bed for thirty minutes rest, after which the post exercise sample was collected to obtain the catecholamines released during muscular work. The total volume of each sample was determined and the results recorded in nanograms of catecholamine excretion. All urine samples were adjusted using concentrated $\mathrm{HCl}$ to a $\mathrm{pH}$ below 2.0 and stored below $4^{\circ} \mathrm{C}$ until analysis for catecholamines was carried out. Diurnal variation was decreased by testing each subject at approximately the same time each day between 6.00 a.m. and 5.30 p.m. and within two hours for test and retest at each reference point. Heart rates were obtained by auscultation at the fourteenth and fifteenth minutes of exercise.

The training regimen consisted of running for thirtyminutes per day, four days each week for twelve weeks. The amount of work was estimated in terms of the distance covered in yards at a rate sufficient to maintain the heart rate at approximately $75 \%$ of the subject's age predicted maximum heart rate (Karvonen, et al., 1957). Each subject recorded his own carotid pulse rate. The total distance walked and run in the thirty-minutes was recorded.

The urinary catecholamines were measured by the fluorometric analysis using a modified version (Bio-Rad catecholamine procedure 1972) of the trihydroxyindole method (Crout, 1961).

\section{Statistical Methods}

The test one and test two samples for the pre $\left(R_{1}\right)$. and mid $\left(R_{2}\right)$, and post $\left(R_{3}\right)$ testing periods were used to calculate the reliability of the adrenaline and noradrenaline measurements for all twenty-eight subjects. Because of the suspected inter-relationships between the dependent variables, adrenaline and noradrenaline, the data were analysed by both univariate and multivariate statistics.
Two analyses were computed, one for the effects of the first six weeks training and the other for the effects of the second six weeks training. A discriminant function analysis was computed to ascertain the proportional distribution of the variance among the dependent variables, exercise noradrenaline, resting noradrenaline, exercise adrenaline, resting adrenaline.

\section{RESULTS}

The reproducibility of the adrenaline, noradrenaline and heart measurements, between test one and test two for pre- $\mathbf{R}_{1}$, and mid- $\mathbf{R}_{2}$, and post- $\mathbf{R}_{3}$, for all twentyeight subjects was high for noradrenaline $(r=0.97-0.98)$ and low for adrenaline $(r=0.01-0.48)$. The reliability for heartrate ranged from .90 to .93 for the three test/retest determinations. The $t$ ratios between all test/retest mean scores were not significant $(P>.05)$ and therefore, no day effect in any measurement was found.

The training in this experiment brought about an improved circulatory regulation characterised by a significant decrease in heart rate during submaximal exercise (157 to $141 \mathrm{bt} / \mathrm{min}$ over first six weeks $(P<$ $.01)$ and 141 to $136 \mathrm{bt} / \mathrm{min}$ over second six weeks). There was a significant increase in distance run from week one to week twelve, 28.8 miles. There was no significant change in body weight or fat free weight over the twelve weeks in either group.

The means at each reference point and mean differences within treatment group are summarized in Table I. These are within the range of $20-70 \mu \mathrm{g} / \mathrm{day}$ quoted in literature, (Pekkarinen and Pitkanen, 1955; Pitkanen, 1957; Klein, 1968; Crout, 1968). Univariate analysis show the change in catecholamine excretion was significantly different $(P<.05)$ between training and control groups for noradrenaline in both resting and exercise conditions and for adrenaline in only the exercise condition. In each case the catecholamine excretion level decreased in the exercised group. No significant change was found in the resting adrenaline for training versus control groups. No significant interaction of exercise and training period was found for any of the changes in catecholamines indicating the changes in catecholamines for the treatment group versus the control group for the first six weeks of training was not significantly different from the second six weeks.

Four of the twelve correlation coefficients between the dependent variables were statistically significant with RNA and EXNA, and RA and EXA correlating significantly the first six weeks $(r=0.74$ and 0.58$)$, and EXNA and EXA correlating significantly $(r=0.73)$ the second six weeks. Therefore, changes between treatment and control groups were analysed using multivariate analysis to account for this association. 


\section{TABLE I}

The Means and Mean Differences of Urine Catecholamines excretion within Treatment and Control Groups over Twolve Weeks Training $\mathbf{N}=\mathbf{2 8}$

Urine Catecholamine $\mathrm{ng} / \mathrm{min} 1,2$

$\mathbf{R}_{1}$

Treatment Group

$\begin{array}{lc}\text { Control Group } & \\ \text { RNA } & 53 \pm 5.4 \\ \text { ENA } & 104 \pm 11.0 \\ \text { RA } & 19 \pm 3.2 \\ \text { EXA } & 27 \pm 3.2\end{array}$

$$
\begin{aligned}
& 52 \pm 3.3 \\
& 95 \pm 6.4 \\
& 15 \pm 1.2 \\
& 21 \pm 2.1
\end{aligned}
$$

$\mathbf{R}_{\mathbf{3}}$

$$
\begin{gathered}
70 \pm 10.1 \\
113 \pm 11.1 \\
14 \pm 2.2 \\
27 \pm 2.5
\end{gathered}
$$

$$
\begin{gathered}
47 \pm 2.6 \\
81 \pm 5.9 \\
16 \pm 1.9 \\
20 \pm 1.9 \\
\\
78 \pm 8.5 \\
115 \pm 10.1 \\
18 \pm 2.8 \\
26 \pm 3.2
\end{gathered}
$$

$$
\begin{aligned}
& \mathbf{R}_{2} \cdot \mathbf{R}_{1} \\
& \text { Mean } \\
& \text { Diff }
\end{aligned}
$$

These

1 Values are $X \pm S E . N=18$ (treatment) and 10 (control).

2 Means based on mean test/retest determination at $R_{1}, R_{2}$ and $R_{3}$.

RNA (resting noradrenaline)

ENA (exercise noradrenaline)

RA (resting adrenaline)

EXA (exercise adrenaline)

The effects of the first and second six weeks training on the changes between treatment and control over all four dependent variables resulted in multiple $F$ ratios of $(P=<0.64)$ and $P=<0.05)$ respectively, this suggests that the training did initiate some change in the resting and exercise excretions of adrenaline and noradrenaline for treatment versus control groups.

A discriminant function analysis was computed to ascertain the proportional distribution of the variance between the catecholamines (Table II).

\section{TABLE II}

\section{Discriminant Function Analysis}

\section{Training Period}

$$
\text { Standardized Coefficients }{ }^{1,2}
$$$$
\text { RNA ENA RA EXA }
$$

$\begin{array}{lrrrr}\text { First six weeks } & -0.62 & 0.07 & 0.10 & -0.81 \\ \text { Second six weeks } & 0.59 & 0.69 & -0.19 & -0.06\end{array}$

1. Standardized discriminant coefficients for resting and exercise $A$ and NA.

2. Discriminant function analysis applied to change in catecholamine excretion over the first six weeks and second six weeks of training.
The discriminate function standardized coefficients indicated that during the first six weeks training, exercise adrenaline and resting noradrenaline were the two variables most discriminating between the treatment and control groups, whilst during the second six weeks, resting and exercise noradrenaline were the most discriminating. In contrast with the first six weeks exercise adrenaline was not affected during the second six weeks.

\section{DISCUSSION}

In many of the studies cited the catecholamines excretion rates were obtained using twenty-four urine collections, and this makes comparisons difficult. When compared to studies using similar collection techniques (Hollister and Moore, 1969; Cronan and Howley, 1974). the resting catecholamine excretion rates in this investigation were appreciably higher. Variation in methodology used to measure catecholamine excretion rates together with the high excretion rates of several subjects, may account for some divergence in results. The emotional reactions of the subjects resulting from personal problems and participation in the experiment could not be ascertained but could have caused an increase in catecholamine excretion. 
The mean catecholamine excretion during exercise (Table I) showed an increase over resting levels. This agrees with previous studies (von Euler et al., 1952; Karki, 1956; Nikkila, 1965; Crout, 1968). The variations between individual adrenaline excretions was quite high, this has been substantiated by Blanksby (1969) using rats, and by direct catheterisation of the left adrenal vein in conscious humans by Sapira and Bron (1971).

Resting noradrenaline seemed to be the most consistent discriminating factor over the twelve weeks (discriminant function coefficients $=-\mathbf{0 . 6 0}$ and $\mathbf{- 0 . 5 9}$ for the first and second six weeks of training, respectively).

The data suggests that programmed exercise may bring about a decrease in the excretion of catecholamines. This is in agreement with the findings of Carlsson et al., (1968), DeSchryver et al., (1967), Wolfson et al., (1972) and Hartley et al., (1972), but is contrary to the findings of Cronan and Howley (1974), who, found no decrease in the excretion of noradrenaline and adrenaline throughout eight weeks of training. They found little change in $\mathrm{VO}_{2}$ max associated with the training programme and speculated that $\mathrm{VO}_{2}$ max would have to change considerably for noradrenaline excretion to decrease. An increase in $\mathrm{VoO}_{2}$ max with training would reduce the relative stress of a constant work load exercise test resulting in lower noradrenaline excretion at that particular work load. This would be consistent with the findings of this study.

\section{REFERENCES}

Bio-Rad, 1972, "Catecholamine Instruction Manual", Bio-Rad Laboratories, California p. 1.

Blanksby, B. 1969, "Base Level Changes of Plasma Catecholamine Concentrations in Albino Rats Following Exhaustive Exercise", Unpublished Ph.D. Thesis, University of Oregon.

Brunner, D. and Manelis, G. 1971, "Physical Activity at Work and Ischaemic Heart Disease", in Larson, O. A. and Malmborg, R. O., (Eds.): Coronary Heart Disease and Physical Fitness. Baltimore: University Park Press, p. 244.

Carlsson, C., Dencker, S. J., Grimsby, G. and Haggendal, J. 1968, “Circulatory Studies During Physical Exercise in Mentally Disordered Patients. II Effects of Physical Training in Patients With and Without Administration of Chlorpromaxine". Acta Med.Scand, 184, 511.

Cronan, L. T. and Howley, H. T. 1974, "The Effect of Training on Epinephrine and Norepinephrine Excretion", Medicine and Science in Sport, 6, 122.

Crout, J. R. 1961, "Catecholamines in Urine", Standard Methods of Clinical Chemistry, New York Academic Press, 3, p. 62.

Crout, J. R. 1968, "Sampling and Analysis of Catecholamines and Metabolites", Anesthesiology, 29: p. 661.

DeSchryver, C., DeHart, P., and Lammerant, J. 1967, "Effect of Physical Training on Cardiac Catecholamine Concentrations", Nature, 214: p. 907.

Ekstein, R. 1957, "Effect of Exercise and Coronary Arterial Narrowing on Coronary Collateral Circulation", Circ. Res., 5: 230.

Harrison, T. 1962, "Part III - The Heart and Blood Vessels and the Kidney: Ischaemic Heart Disease," "The Year Book of Medicine, Chicago: Year Book of Medicine Publishers, p. 255.

Hartley, H. L., Mason, J. W., Hogan, P. R., Jones, L. G., Kotchen, A. T., Mougey, H. E., Wherry, E. F., Pennington, L. L. and Ricketts, P. T. 1972, "Multiple Hormonal Responses to Prolonged Exercise in Relation to Physical Training", J.Appl.Physiol., 33: 607.

Hawthorne, V. M. 1976, "Exercise and the Prevention of Coronary Heart Disease", Brit.J.Sports Med., $10,80$.

Hollister, L. E., and Moore, F. 1969, "Urine Flow and Catecholamines in Man”, Pharm. Res. Commun., 1, 36.

Kannel, B. W., Gordon, T., Sortie, P., and McNamara, P. M. 1971, "Physical Activity and Coronary Vulnerability. Framingham Study", Cardiology Digest, 6, p. 28. 
Karki, N. T. 1956, "The Urinary Excretion of Noradrenaline and Adrenaline in Different Age Groups, its Diurnal Variation and the Effect of Muscular Work on it", Acta.Physiol.Scand., 39: Suppl. 132.

Karvonen, M. J., Kentala, E., and Mustala, O. 1957, "The Effects of Training on Heart Rate". A Longitudinal Study. Ann.Med.Exper.Fenn., 35: p. 307.

Klein, K. F., Toryer, W. G., Thompson, H. K., Bogdonoff, M. D. and Wallace, A. G., 1968, “Catecholamines Excretion in Myocardial Infarction", Arch. Intern.Med., 122: p. 476.

Nikkila, E. A., Torsti, P. and Penntila, O. 1965, "Effects of Fasting, Exercise and Reserpine on Catecholamine Content and Lipoprotein Lipase Activity of Rat Heart and Adipose Tissue", Life Sci., 4: p. 27.

Pascale, L. R., Frankel, T., Grossman, M. I., Freeman, S., Faller, I. L. and Bond, E. 1955, "Denver Report", U.S. Army Med.Nutri. Lab., p. 156.

Pekkerinen, A. and Pitkanen, M. E. 1955, "Noradrenaline and Adrenaline in the Urine. Part II Their Excretion in Certain Normal and Pathological Conditions", Scand.J.Clin. Lab.Invest., 7: p. 8.

Pitkanen, M. E. 1957, "Studies on the Determination and Excretion of Adrenaline and Noradrenaline in the Urine", Acta.Physiol..Scand., 33: Suppl. p. 39.

Regan, T. J., Moschos, C. B., Oldewurtel, H. A. and Helms, H. K. 1966, "Metabolic Role of Catecholamine and the Production of Myocardial Necrosis", Prevention of Ischaemic Heart Disease, Springfield: C. C. Thomas, p. 5.

von Euler, U. S. and Hellner, S. 1951, "Excretion of Noradrenaline and Adrenaline and Hydroxytyramine in Urine", Acta.Physiol.Scand., 22: p. 161.

von Euler, U. S. and Hellner, S. 1952, "Excretion of Noradrenaline and Adrenaline in Muscular Work", Acta.Physiol.Scand., 26: p. 183.

von Euler, U. S. 1955, “Noradrenaline in Hypotensive States and Shock", Lancet, 269: p. 151.

von Euler, U. S. 1969, "Sympatho-adrenal activity and Physical Exercise", in: J. R. Poortmans Biochemistry of Exercise. Medicine and Sport, New York. Karger, Basel, 3: 170. 